\title{
Impact of COVID-19 Lockdowns on Patients Undergoing Orthodontic Treatment
}

\author{
Erum Behroz Khan, Samar Fatima, Mairah Shah, Zuhair Ahmed, Sohail Khan, Sunia

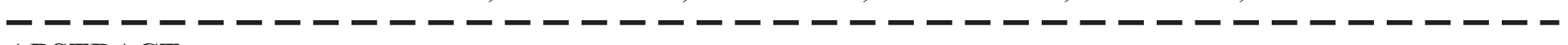

\section{ABSTRACT:}

Objective: To determine the awareness of regular orthodontic follow-up visits among the patients. The secondary objective was to assess patients' perception towards orthodontic treatment needs and their psychological status during lockdown.

Study Design and Setting: This cross-sectional study was conducted at Sindh Institute of Oral Health Sciences, (JSMU) from August, 2020 to January, 2021.

Methodology: The questionnaire contained 15 questions divided into 3 categories. First category was about the awareness of routine checkup among patients Q1-Q5, second was to assess the impact of lockdown on patients' visit to orthodontist Q6-Q12 and third was to assess the psycho-social effect of lockdown Q13-Q15. Three point likert scale was applied on each question with cut off value set as $70 \%$ for the 3 categories to get positive/negative response. SPSS version 22 was used for data entry and analyzing. Percentages and frequencies were calculated for qualitative variables like age, gender and educational level. Chi-square test was applied on all the three categories keeping the p-value $<0.05$ as significant.

Results: The study included 115 subjects comprising of 21(18.3\%) males and 94(81.7\%) females, aged 12-30 years with mean age $19.15 \pm 3.96$. Out of 115 patients $47(40.9 \%)$ patients met the $70 \%$ cut off criteria for category 1.Similarly, for category $2,73(63.5 \%)$ patients met the $70 \%$ cut off value. For category $3,7(6.1 \%)$ patients met the $70 \%$ cut off value. Statistically significant difference was found for category 1 with age, gender and educational level at p-value $<0.05$. Similarly, in category 3 , only educational level showed statistically significant association.

Conclusion: The patients were quite aware of the need to visit orthodontists for regular follow ups during their treatment. The psychological status of the patients was the prime concern of the orthodontists as they had not sought orthodontic help during this time.

Keywords: COVID-19, Lockdown, Patients' Psychology, Treatment needs.

How to cite this Article: How to cite this Article:

Khan EB, Fatima S, Shah M, Ahmed Z, Khan S, Sonia. Impact of COVID-19 Lockdowns on Patients Undergoing Orthodontic Treatment J Bahria Uni Med Dental Coll. 2021; 11(3):107-111 DOI: https://doi.org/10.51985/XZYS1445

This is an Open Access article distributed under the terms of the Creative Commons Attriution Non Commercial Liciense (http/// creativecommons/org/licences/by-nc/4.0) which permits unrestricted non commercial use, distribution and reproduction in any medium, provided the original work is properly cited.

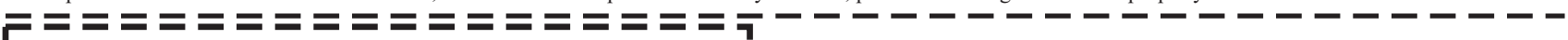

Erum Behroz Khan

I Associate Professor, Head Department of Orthodontics

I Vice Principal-Academics, Saidu College of Dentistry,

Saidu Sharif, Swat, KPK.

I Email: erumbehroz@gmail.com

I Samar Fatima

I FCPS Post Graduate Trainee, year 3, Department of Orthodontics

Sindh Institute of Oral Health Sciences, (JSMU)

I

Mairah Shah

FCPS Post Graduate Trainee, year 3, Department of

Orthodontics

Sindh Institute of Oral Health Sciences, (JSMU)

Zuhair Ahmed

FCPS Post Graduate Trainee, year 3, Department of

Orthodontics

I Sindh Institute of Oral Health Sciences, (JSMU)

I Sohail Khan

I FCPS Post Graduate Trainee, year 3, Department of Orthodontics

I Sindh Institute of Oral Health Sciences, (JSMU)

I Sunia

I FCPS Post Graduate Trainee, year 3, Department of

Orthodontics

Sindh Institute of Oral Health Sciences, (JSMU)

Received: 18-03-2021

Accepted: 24-06-2021

\section{INTRODUCTION:}

The epidemics of Corona virus disease (COVID-19) was originated from Wuhan (China) in December 2019.The Chinese Center for Disease Control and Prevention considered novel Corona virus as the official causative pathogen for this disease on 8 , January 2020.This virus was named initially as $2019-\mathrm{NCoV}-2^{1,2}$ and officially as severe acute respiratory syndrome Corona virus 2 (SARS CoV2). The World Health Organization (WHO) on January 30 , 2020 declared this virus outbreak as medical emergency internationally as it was a challenging public health problem prevalent throughout the world. ${ }^{3}$ On March 27, 2020 WHO reported an update on COVID-19 i.e more than 500,000 cases and 23000 deaths. The COVID-19 outbreak originating from China spread exponentially throughout the world as major public health crisis., ${ }^{4,5} 6$

On 26,February 2020 Pakistan confirmed the COVID-19 two cases i.e a student in Karachi who had just returned from Iran and another case in Islamabad. The province of has recorded the most cases at about 134,000, and has also recorded the most deaths due to COVID-19, about 2,500 
till April-2021. The country was put under a nation-wide lockdown from March $24^{\text {th } 7} 8.9$ Upon its end officially on $1^{\text {st }}$ May, the lockdown was eased in phases. ${ }^{8,9}$

In the dental OPD, the dentists, dental assistant and patients are at increased risk of getting infected with the virus due to the aerosols produced from using high speed hand-piece or doing ultrasonic procedures. ${ }^{10}$ There is close contact with patients during performing orthodontic procedures. The main transmission routes for the spread of COVID-19 disease were found as close contact and through droplets. According to the study it has been reported previously that in the School and Hospital of Stomatology, Wuhan University corona virus infected 9 dental practitioners. Therefore, to reduce the spread of this disease the dental hospitals and clinics attended only dental emergencies, with shut down of all other routine dental procedures including regular orthodontic procedures especially in the Hubei Province, since January 23,2020 . Thus, this pandemic interrupted the routine followup visits of orthodontic treatment. Furthermore, orthodontic emergencies, such extended wires and loose brackets affected some of the patients, but they could not get effective and timely help from the specialists. ${ }^{11}$ With the increasing outbreak of the disease and rapid rise in cases due to COVID19 pandemic several government throughout the world imposed complete lockdown. Public gatherings, travelling etc were banned. Schools, colleges, universities, private/government offices, several OPDs including dental clinics were closed. As a result only emergency treatment was given to the patients. Hence, without any prior notice orthodontic appointments were also ceased till further notice. In orthodontics, there are usually less encounter with emergencies than regular follow up appointments. However, the importance of monthly check-ups and routine orthodontic appointments has not been understood, as well as the impact of confinement and lack of orthodontic assistance during lockdown on patients in times of need should be determined. ${ }^{12}$ The negative effects are produced on individuals and in the society due to the outbreak of any major epidemic. ${ }^{13}$

The rationale of this study was to determine whether or not the patients consider the regular orthodontic appointments as important as they were. These are the areas that need to be addressed. Therefore, the study was conducted, and a survey was done to assess the COVID-19 lockdowns' impact on patients who are undergoing orthodontic treatment.

This study was aimed to assess the COVID-19 lockdown's impact on patient's visit for orthodontic treatment needs and the psycho-social impact on them during lockdown.

\section{METHODOLOGY:}

This observational cross-sectional study was conducted at Sindh Institute of Oral Health Sciences, (JSMU) from August, 2020 to January, 2021. Non-probability consecutive sampling technique was used to enroll study participants. By using WHO calculator sample size was calculated by taking the response percentage as $17.6 \%$ from previous study ${ }^{12}$, confidence level $95 \%$, margin of error $7 \%$, the calculated sample size was 115. Impact of COVID-19 lockdown on patients was assessed through a questionnaire used in a study ${ }^{10}$ with slight self -modification. It was distributed to orthodontic patients visiting dental OPDs as per appointment. Online questionnaire was also used for those who have access to internet and computer. The questionnaire contained 15 questions divided into 3 categories i.e first category would assess the awareness of routine checkup among patients Q1-Q5, second would assess the impact of lockdown on patients' visit to orthodontist for treatment needs Q6Q12 and third would assess the psycho-social effect of lockdown on their treatment Q13-Q15. Three point likert scale was applied on each question with cut off value set as $70 \%$ for the 3 categories to get positive/negative response. Inclusion criteria were, both genders with age range of 1330 years, patient presenting with complain of mal-aligned teeth and undergoing orthodontic treatment. Exclusion criteria was previously treated orthodontically patients were not enrolled for the study. Institutional Review Board of Jinnah Sindh Medical University provided the ethical approval for this study. Proper written informed consent was taken from all the adult patients and for children it was taken from their guardians. SPSS version 22 was used for data entry and analyzing. Percentages and frequencies were calculated for qualitative variables like age, gender and educational level. Chi-square test was applied on all the three categories keeping the $p$-value $<0.05$ as significant.

\section{RESULTS:}

The study included 115 subjects comprising of 21(18.3\%) males and 94(81.7\%) females, aged 12-30 years with mean age $19.15 \pm 3.96$. Among all the subjects $7(6.1 \%)$ had primary level of education, $27(23.5 \%)$ had secondary level of education and $81(70.4 \%)$ had higher secondary educational level. Out of 115 patients $47(40.9 \%)$ patients met the $70 \%$ cut off criteria for category 1 that shows that the patients had awareness regarding regular follow up visits during lockdown. Similarly, for category 2, 73(63.5\%) patients met the $70 \%$ cut off value showing the impact of lockdown on patients' visit to orthodontist for treatment needs. For category $3,7(6.1 \%)$ patients met the $70 \%$ cut off value showing that the lockdown had psycho social impact on them. No statistically significant difference was found for category 1 with age, gender and educational level. Category 2 showed statistically significant association with age ( $\mathrm{p}$-value $=0.002$ ), educational level ( $\mathrm{p}$-value $=0.001)$ and highly significant association with gender ( $\mathrm{p}$-value $=0.000$ ). Similarly, category 3 showed statistically significant association only with educational level ( $\mathrm{p}$-value $=0.003$ ).

\section{DISCUSSION:}

This lockdown has caused many difficulties for the patients undergoing orthodontic treatment. This study aimed to assess 
Table 1: Responses to the Questionnaire in Frequency and Percentage

\begin{tabular}{|c|c|c|c|}
\hline QUESTION & AGREE & NEUTRAL & DIS AGREE \\
\hline 1. Has it been more than 2 months since you visited your orthodontist? & $113(98.3)$ & $0(0)$ & $2(1.7)$ \\
\hline $\begin{array}{l}\text { 2. Are you worried that you are not getting to go for regular follow ups for your } \\
\text { treatment? }\end{array}$ & 103(89.6) & $5(4.3)$ & $7(6.1)$ \\
\hline $\begin{array}{l}\text { 3. Are you following all the instructions given by your orthodontist, such as wearing } \\
\text { of elastics and other oral hygiene instructions? }\end{array}$ & $106(92.2)$ & $9(7.8)$ & $0(0)$ \\
\hline 4. Have you been in touch with your orthodontist? & $46(40)$ & $8(7)$ & $61(53)$ \\
\hline 5. Does your orthodontist check on you regularly? & $18(15.7)$ & $9(7.8)$ & $88(76.5)$ \\
\hline 6. Are you worried regarding your treatment that it will take more time now? & 107(93) & $2(1.7)$ & $6(5.2)$ \\
\hline $\begin{array}{l}\text { 7. Since the lockdown started, have you had any problems with anything fixed in } \\
\text { your mouth (eg, brackets, elastics, appliances and plates)? }\end{array}$ & $74(64.3)$ & $4(3.5)$ & $37(32.2)$ \\
\hline $\begin{array}{l}\text { 8. Are poking wires, broken brackets and elastics coming out of mouth the most } \\
\text { common problems you have faced? }\end{array}$ & $79(68.7)$ & $2(1.7)$ & $34(29.6)$ \\
\hline $\begin{array}{l}\text { 9. Have you suffered from any emergency such as pain, swelling, lacerations/ cuts, } \\
\text { etc., due to treatment since the lockdown? }\end{array}$ & $56(48.7)$ & $7(6.1)$ & $52(45.2)$ \\
\hline 10. Do you think that orthodontic treatment should be considered an emergency? & $57(49.6)$ & $14(12.2)$ & $44(38.3)$ \\
\hline 11. Do you think this lockdown is affecting you more than your orthodontist? & $64(55.7)$ & $41(35.7)$ & $10(8.7)$ \\
\hline $\begin{array}{l}\text { 12. This lock down has made you to realize the importance of being regular with } \\
\text { your appointments? }\end{array}$ & $112(97.4)$ & $0(0)$ & $3(2.6)$ \\
\hline 13. Do you think about your treatment cost will increase following the lockdown? & $26(22.6)$ & $20(17.4)$ & $69(60)$ \\
\hline $\begin{array}{l}\text { 14. Following this lockdown, do you plan to visit your orthodontist as soon as } \\
\text { possible? }\end{array}$ & $113(98.3)$ & $1(0.9)$ & $1(0.9)$ \\
\hline 15. Are you scared to visit your orthodontist after the lockdown ends? & $23(20)$ & $5(4.3)$ & $87(75.7)$ \\
\hline
\end{tabular}

the treatment progress expectations, regular follow up awareness, emergency considerations and the psycho-social impact of lockdown on patients. The study results revealed that most of the patients faced difficulties due to lack of access to orthodontic care.

Total $98.3 \%$ patients revealed that it had been more than 2 months since they last visited their orthodontists. The biggest challenge faced by orthodontic patients is to maintain their oral hygiene. The accumulating plaque around the fixed orthodontic appliance results in demineralization i.e white spot lesions around brackets and bands leading to carious lesions ${ }^{14}$ If patients do not strictly follow the oral hygiene instructions due to prolonged treatment duration, then the plaque accumulation is inevitable. Therefore it is necessary to for orthodontic patient to visit dental OPD on regular basis so that the orthodontist can have check on their current plaque accumulation and oral hygiene status. Subsequently, planning for the management ${ }^{15-17}$

The regular follow up visits are also important for the treatment progress for most of the mechanics applied in orthodontics. For example, the elastics used for retraction or for closing the extraction spaces can become loose or tear. Even plaque accumulation can take place around these elastics leading to caries and ultimately effecting the treatment. But, these problems are mostly ignored by the patients. Poking wires, loose bands/brackets and lacerations/cuts are usually noticed by patients as inconvenient which can have negative effect on orthodontic treatment.

Orthodontic emergencies or appointments were most commonly due to the loosening of bondable buccal tubes or brackets, followed by the loose bands as stated by Rajesh Gyawali et al. ${ }^{18}$ The other possible reasons were, detachment of buccal tubes from the band, tearing of bands, trauma caused by the overextended distal wire to the mucosa, loose ligature ties, dislodgement of elastomeric chains and breakage of acrylic plates ${ }^{18}$ Total $68.7 \%$ of the patients reported in our study that they had commonly faced problems regarding poking wires, broken brackets and loose elastics as compare the study that stated that most of the patients did not face any problems. Approximately $48.7 \%$ patients had pain, swelling, lacerations and cuts due to orthodontic treatment. Relating this to the same study, most of the patients did not had any pain, swelling, lacerations and cuts. ${ }^{12}$ In a study Caprioglio et al and Suri et al advised some methods to deal 
orthodontic emergencies by the patient themselves i.e they can cut the over-extended poking wires through nail cutters, or can also apply disclosing wax that is available over the counter for relief, and through assistance virtually ${ }^{19,20}$

As stated by Rokyo et al that compliance and the length of the orthodontic treatment and the patient's compliance were inversely proportional to each other that is compliance is weak in case of longer treatment durations and vice versa. Therefore, there is a possible chance for the reduction in compliance of patients during the lockdown, though in the current study, $92.2 \%$ of patients reported that they were following all instructions previously given to them.${ }^{16}$ Total $89.6 \%$ patients were worried regarding their loss to follow up visits due to lockdown, which can be the most commonly due to anticipated increase in the treatment duration (93\%). This shows the awareness regarding importance of the need for regular appointments i.e $97.4 \%$ of patients stated that the lockdown had made them realize the importance of regular follow-ups.

Total $5.2 \%$ of patients were not worried about their treatment, the probable reason can be that those had some external motivation and lack active interest in the treatment, or patients who did not encounter any problems during this pandemic lockdown (32.2\%)..However, this does not represent the majority of patients affected. Total $40 \%$ patients were in contact with their orthodontists while $53 \%$ were not. The reason for these results could again be the lack of interest, fear of orthodontic treatment, or could be the problems faced by them during their treatment. Another possible reason could be the lack of access to the orthodontist i.e unavailability of transport or facility, instead of need. From orthodontists' perspective following-up on their patients as much as possible is also necessary, $76.5 \%$ of the patients stated that no calls were received from their orthodontists. This reflects that the orthodontists should be kept in touch with their patients as they are confined to their homes and are worried as they are not getting timely treatment. Small gestures like regular check-up calls can reduce the worry and boost confidence, and give patients reassurance that they are not helpless in this time. This gives the sense of care from orthodontist to the patient. Total $55.7 \%$ of the patients thought that they had been affected by the lockdown more while $35.7 \%$ of the patients thought that both the patient as well as orthodontist was equally affected. This reflects the patients' sympathetic behavior towards the orthodontist during lockdown. When the patients were asked about that orthodontic treatment should be considered as an emergency, results revealed that $49.6 \%$ of the patients considered the problems faced by them as emergency while $38.3 \%$ did not.

A small number of patients reported the fear of increased cost of treatment, i.e $22.6 \%$ shows that the orthodontist should re-ensure patients that, the treatment cost will remain the same if no additional treatment is required (with patients' consent) even post lockdown. And, if any additional cost is increased, it would be utilized for personal protection equipment to ensure safety for both the patient and health care professional.

Total $75.7 \%$ of patients replied that they had no fear at all to visit their orthodontist after the lockdown, the possible explanation for this can be the lack of awareness of the various transmission modes possible for spread of diseases in a dental office with aerosols, close contact of doctors with the patients, etc ${ }^{21}$ Finally, 20\% of the patients showed that they were more concerned about the worldwide COVID19 pandemic. This study thus highlights these patients as they are more concerned about their health, does not consider orthodontic treatment important during lockdown. So, to reassure these patients they should be taken in confident that proper protective measures will be taken to limit the transmission of disease.

\section{CONCLUSION:}

The patients were quite aware of the need to visit orthodontists for regular follow ups during their treatment. The psychological status of the patients was the prime concern of the orthodontists as they had not sought orthodontic help during this time.

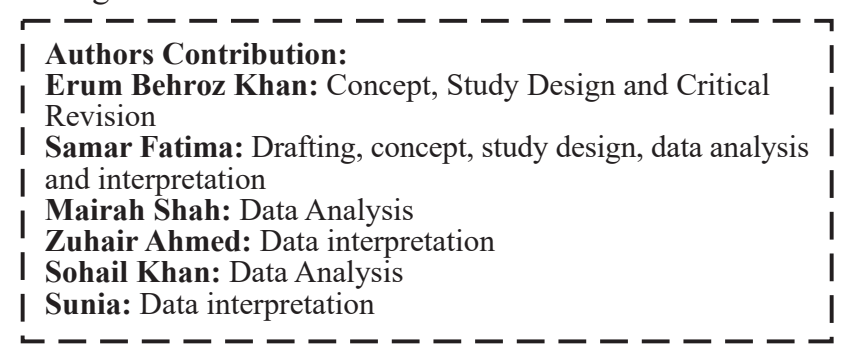

\section{REFERENCES:}

1. Ren YF, Rasubala L, Malmstrom H, Eliav E. Dental care and oral health under the clouds of COVID-19. JDR Clinical \& Translational Research. 2020 Apr 24:2380084420924385.

2. Passarelli PC, Rella E, Manicone PF, Garcia-Godoy F, D'Addona A. The impact of the COVID-19 infection in dentistry. Experimental Biology and Medicine. 2020 21:1535370220928905.

3. $\quad$ Meng L, Hua F, Bian Z. Coronavirus disease 2019 (COVID19): emerging and future challenges for dental and oral medicine. Journal of Dental Research. 2020;99(5):481-7.

4. Ather A, Patel B, Ruparel NB, Diogenes A, Hargreaves KM. Coronavirus disease 19 (COVID-19): implications for clinical dental care. Journal of endodontics. 2020 Apr 6.

5. Prati C, Pelliccioni GA, Sambri V, Chersoni S, Gandolfi MG. COVID-19: its impact on dental schools in Italy, clinical problems in endodontic therapy and general considerations. International endodontic journal. 2020 May;53(5):723.

6. Meng L, Hua F, Bian Z. Coronavirus disease 2019 (COVID$19)$ : emerging and future challenges for dental and oral medicine. Journal of Dental Research. 2020;99(5):481-7.

7. FFDRCSI M. Practice Guidelines Addressing Needs of Pakistani Dentists During the COVID-19 Pandemic Part 1: Needs Assessment 
8. Waris A, Khan AU, Ali M, Ali A, Baset A. COVID-19 outbreak: current scenario of Pakistan. New Microbes and New Infections. 2020 Apr 14:100681.

9. Ali M, Imran M, Khan A. Analysis and Prediction of the COVID-19 outbreak in Pakistan. Journal of Biological Dynamics. 2020 Jan 1;14(1):730-47

10. Meng L, Hua F, Bian Z. Coronavirus disease 2019 (COVID19): emerging and future challenges for dental and oral medicine. Journal of Dental Research. 2020;99(5):481-7.

11. Xiong X, Wu Y, Fang X, Sun W, Ding Q, Yi Y, Huang Y, Gong J, Liu J, Wang J. Mental distress in orthodontic patients during the coronavirus disease 2019 pandemic. American Journal of Orthodontics and Dentofacial Orthopedics. 2020 Jul 10.

12. Shenoi SB, Deshpande S, Jatti R. Impact of COVID-19 Lockdown on Patients Undergoing Orthodontic Treatment: A Questionnaire Study. Journal of Indian Orthodontic Society. 2020;54(3):195-202.

13. Duan L, Zhu G. Psychological interventions for people affected by the COVID-19 epidemic. The Lancet Psychiatry. 2020;7(4):300-2.

14. Huser MC, Baehni PC, Lang R. Effects of orthodontic bands on microbiologic and clinical parameters. Am J Orthod Dentofacial Orthop. 1990;97(3):213-218
15. Bartsch A, Witt E, Sahm G, Schneider S. Correlates of objective patient compliance with removable appliance wear. Am J Orthod Dentofacial Orthop. 1993;104(4):378-386.

16. Royko A, Denes Z, Razouk G. The relationship between the length of orthodontic treatment and patient compliance. Fogorv Sz. 1999;92(3):79-86

17. Baab D, Weinstein P. Longitudinal evaluation of a selfinspection plaque index in periodontal recall patients. J Clin Periodontol. 1986;13(4):313-318.

18. Gyawali R, Pokharel PR, Giri J. Emergency appointments in orthodontics. APOS Trends Orthod. 2019;9(1):40-43.

19. Caprioglio A, Pizzetti GB, Zecca PA, Fastuca R, Maino G, Nanda R. Management of orthodontic emergencies during 2019-NCOV. Prog Orthod. 2020;21:10.

20. Suri S, Vandersluis YR, Kochhar AS, Bhasin R, Abdallah $\mathrm{MN}$. Clinical orthodontic management during the COVID19 pandemic. Angle Orthod. 2020. doi:10.2319/033120-236.1. Online ahead of print.

21. Mousa AA, Mahmoud NM, Tag El Din AM. Knowledge and attitudes of dental patients towards cross-infection control measures in dental practice. East Mediterr Health J. $1997 ; 3(2), 263-273$ 